\title{
The ASEAN Commemorative Conference on Traditional and Complementary Medicine
}

The ASEAN Commemorative Conference on Traditional and Complementary Medicine was held at the Sofitel Philippine Plaza Hotel, Manila, Philippines, from September 25-27, 2017 hosted by the Philippine Government through the efforts of the Department of Health, Bureau of International Cooperation and Philippine Institute of Traditional and Alternative Health Care (PITAHC) (Fig. 1).

Dr. Annabel De Guzman, the new Director General of the Philippine Institute of Traditional and Alternative Health Care (PITAHC) DOH together with other members of the Executive Committee of PITAHC ensured the success of the conference in terms of the number of participants and more importantly in the quality of the scientific program. The conference gathered 140 delegates from the 10 ASEAN Member States. Also invited were participants from China and Timor Leste.

Focus of the presentations made by ten countries were on their best practices of traditional and complementary medicine in their respective countries. In general, the reports indicated the practice of traditional and complementary medicine continues to grow and prosper in the ten ASEAN countries. The governments of these countries support and supervise T\&CM practice through national policies and regulatory bodies. Along with the successes the conference also raised issues and limitations in the practice of T\&CM.

Foremost in the accomplishments is the integration of T\&CM in the nation-

Deutsche Zeitschrift für Akupunktur

2018 • 61 (1): 45

https://doi.org/10.1007/s42212-018-0019-x

Online publiziert: 9 February 2018

๑) Springer Medizin Verlag GmbH, ein Teil von

Springer Nature 2018 al healthcare system including its use in primary health care and in public hospitals. This is being implemented in varying degrees in Thailand, Malaysia, Indonesia, and Burma. In the Philippines and in Singapore, T\&CM services are more available in private clinics, non-government and charitable institutions.

The reluctance of health care professionals to accept the effectiveness of integrating traditional medicine in health care remains a big hindrance to its development. Myanmar was among the ASEAN countries who has established a higher learning education on T\&CM-the University of Traditional Medicine in 2001 which now offers bachelor and masteral degrees in tradional medicine. The conference stressed on the need to do more scientific research on the quality, efficacy and safety of traditional medicine for better acceptance in conventional medical practice.

The conference adopted the following recommendations:

1. Strengthen local/international col-

laboration in the areas of developing

herbal medicines, ensuring quality of

T\&CM products and services, standardization of academic and skills pathway, and information sharing;

2. Empower the public on T\&CM practice by increasing public awareness of available T\&CM products and services and empower the public to report about illegal practices leading to complications and malpractice;

3. Better integration of T\&CM in national health care policies by increasing regulatory power through proper legislations and increasing funding for T\&CM departments and R\&D; and

4. Promote national recognition, awards, and scholarships as motivation for best practices in T\&CM.

The ASEAN Commemorative Conference on Traditional and Complementary Medicine also had an exibition from

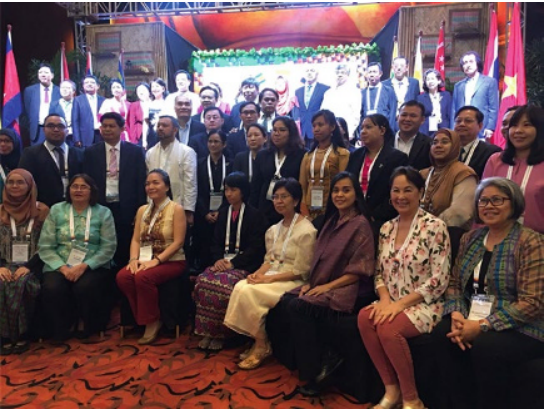

Fig. 1 Photo with country representatives. Janet P. Paredes seated on the right most of the picture

8 ASEAN Member States who shared their updates through a poster presentation in their respective booths. On the last day of the conference, the participants experienced the Filipino traditional "Hilot" also known as Filipino healing massage.

\section{Corresponding address}

Janet Pimentel-Paredes

National Acupuncture Detoxification

Association (NADA) Philippines

Quezon City, Philippines

janetparedes56@gmail.com

Conflict of interest. J. Pimentel-Paredes declares that she has no competing interests. 